\title{
DESPLAZADOS FORZADOS Y SU PARTICIPACIÓN EN EL MERCADO LABORAL COLOMBIANO*
}

\author{
ADRIANA CAROLINA SILVA ARIAS*** \& JAIME ANDRÉS SARMIENTO ESPINEL **** \\ UNIVERSIDAD MILITAR NUEVA GRANADA
}

Recibido/ Received/ Recebido: 03/12/2012 - Aceptado/ Accepted/Aprovado: 28/04/2013

\begin{abstract}
Resumen
La participación en la fuerza de trabajo es el resultado de una multiplicidad de factores. Aislando el efecto de algunos factores relacionados con la condición socio-demográfica de la población desplazada forzada, estimamos un modelo logístico multinomial para explicar el estado ocupacional (inactivo, desocupado y ocupado) en el lugar de destino de los desplazados forzados y otros grupos poblacionales a partir de una submuestra del Censo Colombiano de 2005. Este modelo fue estimado por sexo, ya que los factores que determinan la participación laboral podrían ser diferentes para los varones que para las mujeres. Los resultados de las estimaciones indican que los desplazados forzados, tanto mujeres como varones, reflejaron el carácter estructural de su mayor desocupación. Por otro lado, los desplazados forzados también habrían experimentado desventajas frente al perfil socio-demográfico de los otros migrantes internos y de la población nativa.
\end{abstract}

Palabras clave: Población en desplazamiento forzado, Participación laboral, Modelo logístico multinomial.

\section{FORCIBLY DISPLACED POPULATION AND ITS PARTICIPATION IN COLOMBIAN LABOR MARKET}

\begin{abstract}
Participation in workforce is the result of multiple factors. Excluding some factors related to sociodemographic conditions of forcibly displaced population, we estimated a logistical multinomial model to explain occupational status (inactive, unoccupied and occupied) in the place where forcibly displaced population is located and other population groups from a subsample of Colombian Census 2005. This model was estimated by sex, because factors that determine labor participation may be different for men than for women. Estimation results suggest that forcibly displaced individuals, such women as men, reflected a structural higher unemployment. Furthermore, forcibly displaced individuals also experienced disadvantages compared to socio-demographic profile of other boarder migrants and native population.
\end{abstract}

Keywords: Forcibly displaced population, Labor participation, Multinomial logistic model.

Artículo de investigación, resultado del proyecto de investigación ECO 1222 financiado por la Universidad Militar Nueva Granada. Cabe aclarar que algunos aportes de este artículo se derivan de la tesis para optar por el grado de doctora en Estudios de Población en El Colegio de México titulada "Geografía del Refugio, Sobrevivencia Económica y Vida Familiar de la Población Desplazada Forzada en Colombia" realizada por Adriana Carolina Silva Arias, asesorada por Brígida García y Silvia Giorguli; lector: Manuel Ángel Castillo.

* Economista de la Universidad del Rosario, Magister en Economía de la Universidad de los Andes y Doctora en Estudios de Población de El Colegio de México. Docente investigadora de la Facultad de Ciencias Económicas de la Universidad Militar Nueva Granada y Co-líder del Grupo de Estudios Macroeconómicos - GESMA. Correo electrónico: adriana.silva@unimilitar.edu.co

*** Economista y Magister en Economía de la Universidad Javeriana y Doctor en Economía de El Colegio de México. Profesor investigador de la Facultad de Ciencias Económicas de la Universidad Militar Nueva Granada y Co-líder del Grupo de Estudios Macroeconómicos GESMA. Correo electrónico: jaime.sarmiento@unimilitar.edu.co 


\title{
RETIRANTES PELA VIOLÊNCIA E SUA PARTICIPAÇÃO NO MERCADO LABORAL COLOMBIANO
}

\begin{abstract}
Resumo
A participação na força de trabalho é o resultado de uma multiplicidade de fatores. Isolando o efeito de alguns fatores relacionados com a condição sóciodemográfica da população retirante por causa da violência, estimamos um modelo logístico multinominal para explicar o estado ocupacional (inativo, desocupado e ocupado) no lugar de destino destes retirantes e outros grupos populacionais a partir de uma submostra do Censo Colombiano de 2005. Este modelo foi estimado por sexo, já que os fatores que determinam a participação laboral poderiam ser diferentes entre homens e mulheres. Os resultados indicam que os retirantes forçados pela violência, tanto mulheres como homens, refletiram o caráter estrutural de sua maior desocupação. Por outro lado, estes retirantes também teriam experimentado desvantagens frente ao perfil sóciodemográfico dos outros migrantes internos e da população nativa.
\end{abstract}

Palavras chave: Retirantes forçados pela violência, Participação laboral, Modelo logístico multinominal.

Silva, A. \& Sarmiento, J. (2013) Desplazados forzados y su participación en el mercado laboral colombiano. En: Revista de la Facultad de Ciencias Económicas de la Universidad Militar Nueva Granada. rev.fac.cienc.econ, XXI (1).

JEL: J01, J81, C38

\section{Introducción}

Los tres países que han tenido más población desplazada forzada en el último decenio han sido Colombia, la República Democrática del Congo y Sudán. En conjunto, representaron casi la mitad de todas las personas desplazadas a nivel mundial (IDMC, 2011). A pesar de la magnitud del problema del desplazamiento forzado en Colombia, y a partir de las dudas que desde el mismo gobierno se plantean acerca de si los desplazados forzados ${ }^{1}$ realmente requieren una asistencia diferenciada de la que requieren otros migrantes internos ${ }^{2}$, este artículo pretende examinar si existieron desventajas en la integración económica de los desplazados forzados internos colombianos en sus lugares de destino.

La hipótesis central del artículo es que los desplazados, además de haber sido forzados a abandonar su lugar de origen por el conflicto armado interno, presentaron una menor participación laboral en los lugares de destino que otros migrantes internos. Esta hipótesis se plantea en razón a que la literatura ha documentado que el perfil socio-económico de los desplazados forzados refleja su legado de pobreza y generalmente un origen rural, por lo que se habrían convertido en parias que se han enfrentado a la discriminación y estigmatización en medio de su afán por contar con un trabajo en los lugares de destino (Ibáñez \& Moya, 2007; Ibáñez, Moya \& Velásquez, 2006; Lozano \& Gómez, 2004).

A lo largo del artículo reconstruimos el perfil diferenciado de los desplazados forzados en Colombia. Como técnica de análisis, utilizamos modelos logísticos multinomiales para evaluar las diferencias en la participación laboral por estatus migratorio (desplazados forzados, otros migrantes internos y nativos).

1 A lo largo del artículo se utilizarán indistintamente las acepciones de migrante forzado, refugiado interno, desplazado forzado y desplazado.

2 "Nosotros no tenemos desplazados, tenemos migración en buena parte por el paramilitarismo y la guerrilla (...) esa gente se fue para ciudades y allá están como migrantes". Apartes de las declaraciones del ex-asesor presidencial, José Obdulio Gaviria, en una conferencia de prensa realizada en Washington el 28 de Julio de 2008. 
De este modo, este artículo evidencia que los desplazados forzados presentaron menores niveles de escolaridad, más individuos en edades consideradas como no laborales, mayor disrupción conyugal, desempleo y pobreza. Así, la mayor contribución de esta investigación es que da cuenta de las principales diferencias en la inserción laboral y el perfil socio-demográfico de los desplazados forzados respecto de los demás migrantes internos y de la población nativa.

Este artículo se organiza como sigue: la sección el desplazamiento forzado en Colombia con información censal identifica el universo de estudio; posteriormente la sección participación en el mercado laboral presenta la participación laboral de la población de acuerdo a la condición migratoria; además, se estima un modelo logístico multinomial en el cual, teniendo en cuenta algunas condiciones sociodemográficas, se estima el efecto que tendría la condición de desplazado forzado sobre la probabilidad de participación en el mercado laboral colombiano. En la sección cuatro se presentan los comentarios finales.

\section{El desplazamiento forzado en Colombia con información censal}

Con el fin de tener representatividad a nivel municipal de los refugiados internos, se utiliza la información del último Censo de población realizado en el 2005, debido a que es la única fuente de información que ofrece dicha representatividad (DANE, 2007, 2008b). Asimismo, el Censo cuenta con información de pertenencia, tanto en origen como en destino, de áreas rurales ${ }^{3}$ o urbanas ${ }^{4}$ (DANE, 2007), que podría ser comparada con otras fuentes de información con las que se puedan identificar algunas características de las zonas de expulsión y de asentamiento de la población desplazada forzada en Colombia. ${ }^{5}$
La identificación del universo de estudio no es trivial, debido a las ambigüedades inherentes al operacionalizar el concepto del desplazamiento forzado y al definir los grupos poblacionales de comparación. Es por esto que esta sección tiene como propósito ir acotando la población, empezando desde los nativos y migrantes internos recientes, hasta delimitar la población desplazada forzada y por contra factual los otros grupos poblacionales de comparación.

\subsection{Categorización según lugar de nacimiento y cambio de residencia: migrantes recientes y nativos}

La primera acotación en el universo de estudio fue la exclusión de las personas que nacieron o procedieron de otros países, dado que el interés de este artículo es, estudiar el desplazamiento forzado a partir de los migrantes internos colombianos ${ }^{6}$. Además, se excluyeron a los migrantes recientes provenientes de otros países que residían en Colombia, dado que tampoco se constituyen en el objeto de estudio.

Por otro lado, debido a que la población menor de cinco años no se encontró expuesta al riesgo de migrar durante los cinco años previos a la aplicación del cuestionario censal, será inicialmente excluida del análisis. ${ }^{7}$ Con respecto al desplazamiento dentro de una misma área metropolitana, obedecería a un fenómeno territorial y humano que no es considerado como migración interna, ya que gran parte de sus habitantes se desplazan diariamente para trabajar en el núcleo urbano central, siendo las poblaciones aledañas en muchos casos poblaciones dormitorio, en las que sus habitantes sólo van a dormir y a pasar el fin de semana. Por esta razón, las personas podrían cambiar de lugar de residencia dentro de la "ciudad real" compuesta por varios municipios, por la seguridad que se ofrece dentro de ellas, o por

\footnotetext{
Incluye centros poblados, corregimientos, inspecciones de policía, caseríos, veredas y el campo.

Población que se ubica en las cabeceras municipales, que es donde se encuentra ubicada la alcaldía.

En cuanto a la cobertura censal, de los 1.122 municipios colombianos, el 76\% (848 municipios) presentaron menos de 5\% de omisión censal. Sin embargo, el porcentaje restante de municipios pudo haber concentrado población desplazada forzada, dado que las limitaciones en la cobertura y en la calidad de los datos censales son más sensibles en las zonas de alta incidencia del conflicto armado. No obstante, la información del 2005 fue la que mejor cobertura ha tenido en la historia de los Censos, en gran parte debido a la actualización cartográfica (DANE, 2007).

6 Esta población representó menos del 1\% de la población total colombiana (169.984 personas).

7 De esta manera también se eliminan los problemas de sub-registro, puesto que de acuerdo al documento del proceso de cierre del Censo elaborado por el DANE (2008), se presentaron inconsistencias en las tasas de fecundidad, mortalidad y en la relación hombre/mujer de la población menor de cinco años registrada en la información censal.
} 
cualquier otra preferencia, como la distancia al trabajo $^{8}$. Por tanto, 81 municipios colombianos fueron recodificados dentro de los 17 municipios núcleo de las 17 áreas metropolitanas 9 . De esta manera, la población que se consideró como migrante reciente se redujo a una tercera parte de lo que habría sido considerada inicialmente. Es decir, los migrantes recientes representaron tan sólo el $13 \%$ de la población total.

Se consideró como población nativa a la población que no cambió de municipio/área metropolitana de residencia durante los cinco años previos a la aplicación del cuestionario censal, y que éste(a) coincidió con el municipio/área metropolitana de nacimiento. De tal forma, se adicionó a la población nativa, las personas que sí habían cambiado de residencia, pero dentro del mismo municipio/área metropolitana y ese(a) municipio/área metropolitana coincidía con el municipio/área metropolitana del lugar de nacimiento. De acuerdo a estas consideraciones, la población nativa representó el 86\% de la población total.

\subsection{Categorización migrantes recientes: desplazados forzados y otros migrantes internos}

A partir de la población migrante interna reciente, se consideran entonces como desplazados forzados a las personas que cambiaron de municipio de residencia ${ }^{10}$ y que respondieron que la principal causa por la que cambiaron su lugar de residencia durante los cinco años previos a la aplicación del Censo de 2005 (periodo de desplazamiento entre 20002005), fue debido a amenazas o riesgo contra su vida, su libertad o su integridad física ocasionados por la violencia.
Se considera que uno de los grupos poblacionales con los que se podría comparar los desplazados forzados, es el de los migrantes forzados por "fenómenos naturales", que corresponde a los migrantes recientes que contestaron que la principal causa por la que cambiaron su lugar de residencia durante los cinco años previos a la aplicación del Censo fue debido al "riesgo de desastre natural".

Igualmente, se considera como otro de los grupos poblacionales de comparación el de los "migrantes voluntarios", conformado por las personas que indicaron que la principal causa por la que cambiaron su lugar de residencia, nuevamente durante los cinco años previos a la aplicación del Censo, fue a causa de la dificultad para encontrar trabajo, a la ausencia de medios de subsistencia, a necesidades de educación, por motivos de salud, debido a razones familiares, por ser miembro de un pueblo nómada u otra razón. La Ilustración 1 muestra el esquema explicativo completo de las categorías de análisis de la población desplazada forzada, así como los grupos poblacionales con los cuales podría ser comparada.

\subsection{Una aproximación a la magnitud de desplazados forzados en Colombia}

En la Tabla 1 se presenta la información del volumen de migrantes recientes y nativos que se captan mediante la información censal. Los migrantes forzados inter-municipales, aunque se refieren únicamente a los desplazados forzados a causa de la violencia generalizada, representaron el $1,1 \%$ de la población colombiana durante el 2005 y el $8 \%$ del total de la población migrante reciente.

8 La proporción de migrantes recientes intra-municipales (voluntarios, desplazados forzados y forzados por fenómenos naturales) correspondientes a las 17 áreas metropolitanas fue del 59\%; los correspondientes a las otras capitales, diferentes a las de las áreas metropolitanas, representaron el 4\%; finalmente, el resto de migrantes recientes intra-municipales que agruparon el $97 \%$ de los municipios, representaron el 37\%.

9 Las áreas metropolitanas vigentes en Colombia, de acuerdo a su orden de creación, que inicialmente fueron consideradas son: Medellín, Bucaramanga, Barranquilla, Cúcuta, Centro Occidente y Valledupar. También fueron consideradas las áreas metropolitanas reconocidas pero no configuradas: Bogotá, Cali, Popayán, Villavicencio, Girardot, Cartagena, Manizales, Santa Marta, Armenia, Sincelejo e Ibagué.

10 En la definición de los migrantes recientes, se excluyeron los desplazados forzados intra-municipales, ya que en su mayoría pertenecieron a municipios urbanizados, donde la incidencia de los actores armados por el conflicto interno podría ser menor. En este sentido, la sobre-estimación de la población nativa debido a la recodificación de desplazados forzados intra-municipales como nativos no resultó significativa, ya que esta recodificación representó tan sólo el 0,2\% de la población total, mientras que la población nativa representó el $86 \%$ de la población total considerada. 
Ilustración 1. Esquema explicativo de la categorización del universo de estudio de acuerdo al cuestionario del Censo de $2005^{11}$

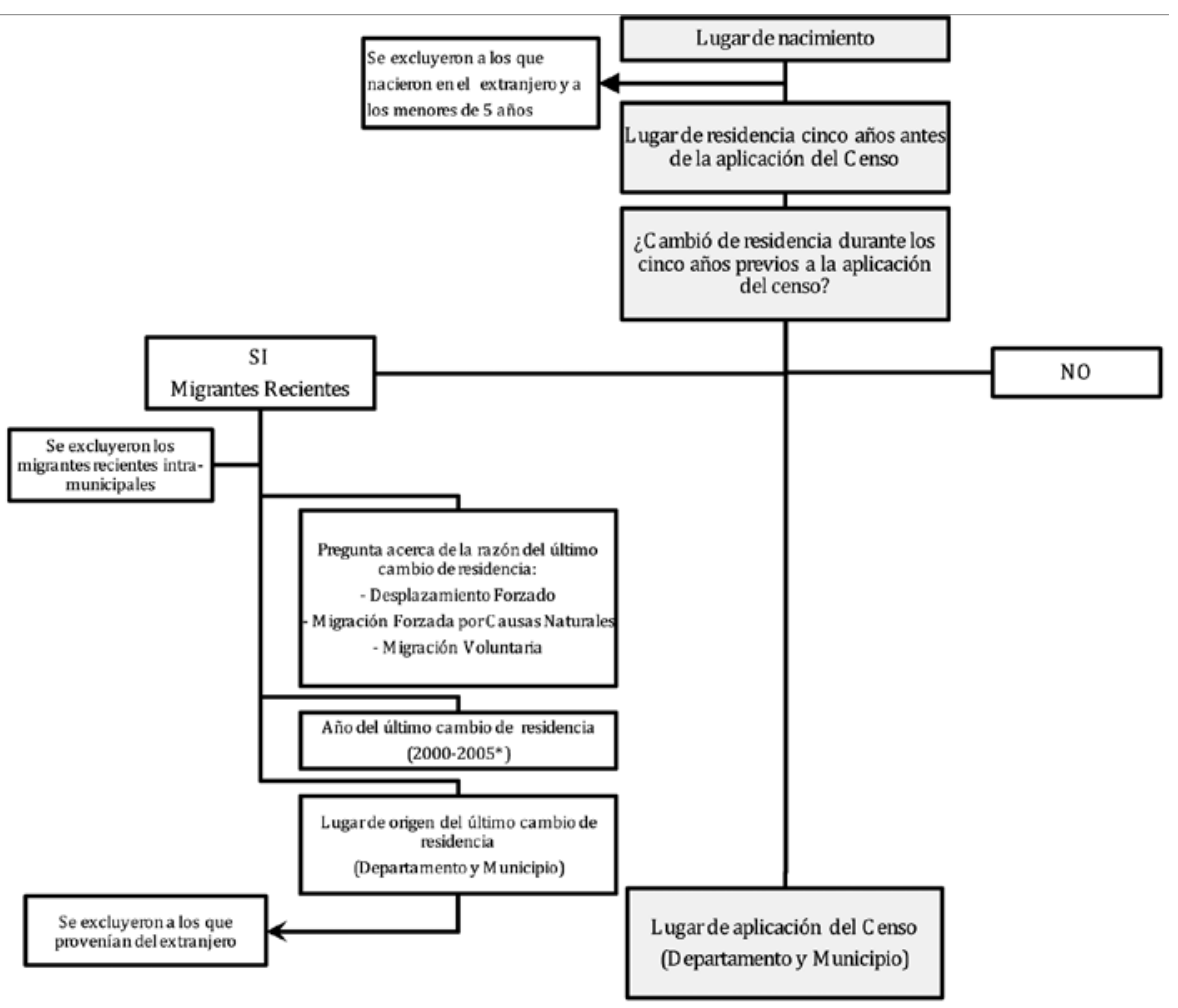

Tabla 1. Magnitud de los migrantes recientes y nativos en Colombia (2000-2005) ${ }^{12}$

\begin{tabular}{lccc}
\hline \multicolumn{1}{c}{ Tipo de Migrante Reciente } & Volumen & Porcentaje & $\begin{array}{c}\text { Porcentaje de Migrantes } \\
\text { Recientes }\end{array}$ \\
\hline Voluntarios & 2.945 .209 & $12,1 \%$ & $88,3 \%$ \\
\hline Desplazados Forzados & 274.716 & $1,1 \%$ & $8,2 \%$ \\
\hline Migrantes Forzados por Fenómenos Naturales & 116.960 & $0,5 \%$ & $3,5 \%$ \\
\hline Total Migrantes Recientes & 3.336 .885 & $13,7 \%$ & $100 \%$ \\
\hline Nativos & 20.986 .927 & $86,3 \%$ & \\
\hline POBLACIÓN TOTAL* & 24.323 .812 & $100 \%$ & \\
\hline
\end{tabular}

Para fines comparativos y sin realizar algún otro tipo de consideración, es importante mencionar que Acción Social como fuente oficial de registro reportó que 1.930.141 personas habrían sido desplazadas forzadas y registradas en el Registro Único para la Población Desplazada - RUPD entre el 2000 y

11 Fuente: Imagen de la investigación.

12 Fuente: Cálculos propios a partir del Censo de 2005 (DANE). * La población total corresponde a la población total considerada después de los refinamientos de la base de datos anteriormente mencionados. 
$2005 .{ }^{13}$ Además, si se descuenta el 3\% de esta población, que correspondería a la población que se estimó por el RUPD como menor de 5 años durante el periodo de análisis (con el fin de comparar esta cifra con el volumen de población desplazada forzada que se identificó a partir de la información del Censo de 2005), se calculó que aproximadamente la cifra de desplazados registrada en la información de Acción Social sería de alrededor de 1.833 .634 personas. Por tanto, el Censo estaría captando aproximadamente un 15\% del total de desplazados forzados de los que podrían haber accedido al RUPD.

Así, frente a las estadísticas sobre el registro oficial de desplazados suministradas por Acción Social de la Presidencia de la República, la información censal aparecería sustancialmente como sub-registrada. En este sentido, el DANE atribuye este sub-registro a algo inevitable: que el desplazado "por miedo, prefiere no declarar su condición en censos y encuestas o, atribuyen la migración a razones familiares, ya que en un gran número de oportunidades, al efectuarse el desplazamiento, acuden a ellos para tener vivienda temporal" (DANE, 2008a, 41-42).

Los desplazados que capta la información del Censo de 2005 fueron los que cambiaron de municipio/ área metropolitana de residencia durante los cinco años previos y que permanecían en un municipio/ área metropolitana de residencia distinta, dejando de considerar los que se desplazaron solamente durante el periodo de emergencia o los desplazados forzados circulares que posteriormente retornaron nuevamente a su lugar habitual de residencia. $\mathrm{Al}$ mismo tiempo, el universo de estudio se refiere a los desplazados forzados a causa de la violencia generalizada, dejando de lado los desplazados forzados a causa de otras situaciones como conflicto armado interno, disturbios o tensiones interiores, violaciones masivas de los derechos humanos, infracciones al Derecho Internacional Humanitario (DIH) y alteración del orden público, las cuales también son contempladas en la definición del desplazamiento forzado estipulada en la Ley 387 de 1997.
Además, dado que el Censo de 2005 es un sistema de información que no tiene implicaciones de reconocimiento para acceder a la asistencia de las políticas estatales, las personas podrían ponderar de otra forma la motivación principal que reconocen como detonante de la migración. Los desplazados forzados declaran otras razones de migración que también forman parte de la vulnerabilidad social que los caracteriza, pero que no les podría implicar una estigmatización o brindar mayores explicaciones sobre hechos dolorosos que la misma población quiere pasar al olvido.

Ante este escenario, se evaluaron varias posibilidades para imputar el estatus de desplazados forzados a algunas personas que habían sido identificadas como otros migrantes internos e incluso como nativos, como alternativas para disminuir el grado de subestimación. En primer lugar, dado que la información del Censo de 2005 no captó un gran volumen de migrantes intra-municipales, razón por la cual fue delimitado el universo de estudio a los desplazados forzados inter-municipales (los que vivían en otro municipio/área metropolitana), se evaluó la posibilidad de estimar el volumen de refugiados internos intra-municipales que fueron registrados oficialmente en el RUPD por Acción Social, pero que no fueron registrados en el Censo por el DANE. Sin embargo, dada la forma en que son presentados los tabulados del RUPD publicados por Acción Social, resultó imposible rastrear al mismo tiempo los lugares de origen y los lugares de asentamiento de los refugiados internos (matrices de migración), por lo que se descartó la posibilidad de estimar el volumen de desplazados forzados intra-municipales con base en la información oficial disponible. Por tanto, no fue posible estimar el volumen de desplazados forzados intra-municipales, quienes habrían sido identificados como población nativa.

También se evaluó la posibilidad de imputar el estatus de desplazado forzado a los migrantes recientes que adujeron otras razones de migración, espe-

13 Se realizó la consulta en el Sistema de Información Geográfica para la planeación y el Ordenamiento Territorial - SIGOT del periodo 2000-2005 con fecha de corte anual hasta el 2008. Vale la pena tenerlo presente dado el carácter dinámico de esta información, debido al ajuste periódico que Acción Social realiza cuando una persona es identificada con varios desplazamientos, puesto que registra sólo el último cambio de residencia. 
cialmente a los que declararon que migraron por razones familiares, dado que serían las redes de apoyo familiares a las que comúnmente acudirían para buscar refugio (DANE, 2008a). Sin embargo, cualquier técnica de imputación por lugar de origen o destino de los migrantes recientes (e incluso si se desagregara por año de salida) que se basara en el criterio, por ejemplo de municipios de salida de migrantes recientes con "alto" conflicto armado, sería arbitraria, puesto que podría sesgar la composición demográfica y las características socio-económicas de la población desplazada forzada, lo cual en última instancia influiría en los hallazgos del artículo.

Adicionalmente, se evaluó la viabilidad de asignarle el estatus de desplazado forzado a los migrantes recientes que no fueron categorizados como desplazados forzados, pero que tuvieron algún tipo de vínculo familiar con algún miembro del hogar que sí hubiese sido categorizado como desplazado forzado y que, además, coincidiera con el lugar y el año de salida.
Este tipo de análisis no fue posible realizarlo, dado que se presentó una gran proporción de migrantes recientes que no especificaron su lugar de origen.

Ante esta situación, se evaluó la posibilidad de comparar la información a nivel municipal del Censo con la de Acción Social, para poder estimar un factor de expansión municipal de los migrantes recientes que inicialmente fueron identificados como desplazados forzados durante el periodo 2000-2005 con la información censal. ${ }^{14}$ No obstante, se considera que las cifras no son comparables ni expandibles, debido a que el Censo captó solamente la población que declaró durante el 2005 (y aun en el 2006) que el último cambio de residencia inter-municipal ocurrió durante los cinco años previos a la aplicación del formulario censal, y que la razón de este cambio de residencia fue debido a la violencia generalizada. En cambio, el registro de Acción Social es un dato continuo y que cambia retrospectivamente de acuerdo a la fecha de corte.

Ilustración 2. Proporción de desplazados forzados en Colombia en los lugares de destino (2000-2005) ${ }^{15}$
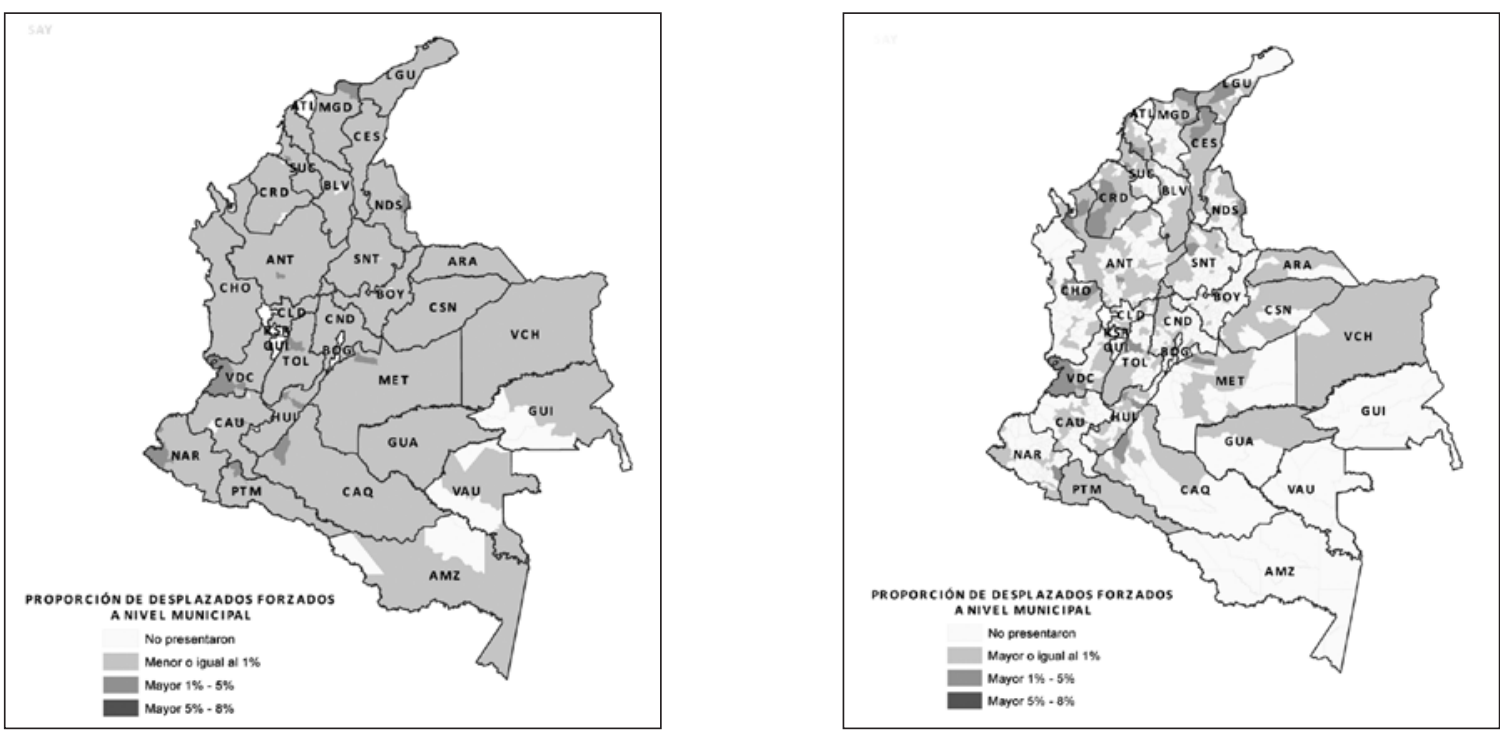

14 Sin embargo, en marzo de 2006 todavía se estaban aplicando formularios de captura de información censal en algunos municipios de Colombia.

15 Fuente: Cálculos propios a partir del Censo General del 2005 (DANE) y Acción Social 2008. 
Al comparar la proporción de desplazados forzados inter-municipales para el periodo 2000-2005 en los lugares de asentamiento registrados por el Censo, con el registro de desplazados que presenta Acción Social para el mismo periodo (Ilustración 2), se evidenció que estas dos fuentes de información mostraron que la distribución en los sitios de recepción de población desplazada forzada no fue homogénea y que habría afectado a la mayoría de municipios del país. Encontramos que la distribución espacial de los desplazados forzados captados por el Censo se presentó en un mayor número de municipios, aunque representen un menor volumen que los que presentan las cifras registradas por Acción Social.

Además, el Censo identifica los desplazados forzados a causa de la violencia generalizada, quienes pudieron no haberse registrado en el RUPD, dado que no necesariamente realizaron la auto-declaración como desplazados forzados, probablemente por el miedo, porque no requerían de ayuda estatal, por temor a ser rechazados en el Registro, porque se les vencieron los términos para el Registro o porque no existían para ese momento criterios unificados para el Registro de la población desplazada forzada. En resumen, se trata de dos fuentes de información que son distintas y no son comparables.

Con todo, a pesar de las limitaciones que presenta la información censal en la identificación de la población refugiada interna, también presenta múltiples ventajas, dado que sería posible captar con dicha información otras características, que no sólo posibilitarían la caracterización de esta población, sino que también permitiría caracterizar los grupos poblacionales de referencia y su comparación con otros migrantes recientes e incluso con la población nativa. De esta forma, se podrían analizar las condiciones diferenciadas en las características poblacionales de los desplazados forzados con el resto de la población, tales como composición por edad, sexo, estado civil y grupo étnico, estructura del hogar, fuerza de trabajo disponible, asistencia escolar, entre otros.

\section{Participación en el mercado laboral}

En esta sección se analizó si habría existido una menor participación en el mercado laboral colombiano de los desplazados forzados con respecto a la de los otros grupos poblacionales, independientemente de sus características socio-económicas por el hecho de "ser-estar desplazado forzado". La estimación del modelo de participación laboral permite realizar un perfil de los participantes en la fuerza laboral, incluyendo su estatus migratorio.

En la Tabla 2 se muestra la composición de la población económicamente activa en Colombia de acuerdo a la información del Censo de 2005. De este modo, se observa que se encontraban ocupados aproximadamente uno de cada nueve colombianos que querían y podían trabajar. Sin embargo, la población desplazada forzada habría presentado la más alta tasa de desocupación (12,9\%) entre todos los grupos poblacionales considerados, aunque esto podría haber sido causado por las características desfavorables de las condiciones sociodemográficas de los refugiados internos colombianos en los lugares de destino.

Tabla 2. Composición de la población económicamente activa en Colombia (2005) ${ }^{16}$

\begin{tabular}{lccccc}
\hline \multirow{2}{*}{ Condición migratoria } & \multicolumn{2}{c}{ Trabajaban } & \multicolumn{2}{c}{ No Trabajaban } & \multirow{2}{*}{ Total PEA } \\
\cline { 2 - 5 } & No. de personas & \% PEA & No. de personas & \% PEA & \\
\hline Desplazados Forzados & 82.155 & $87.1 \%$ & 12.160 & $12.9 \%$ & 94.315 \\
\hline Voluntarios & 1.170 .256 & $93.0 \%$ & 88.625 & $7.0 \%$ & 1.258 .881 \\
\hline Naturales & 37.140 & $93.3 \%$ & 2.654 & $6.7 \%$ & 39.794 \\
\hline Nativos & 6.795 .349 & $91.7 \%$ & 611.057 & $8.3 \%$ & 7.406 .406 \\
\hline Total & 8.084 .900 & $91.9 \%$ & 714.496 & $8.1 \%$ & 8.799 .396 \\
\hline
\end{tabular}

16 Fuente: Cálculos propios a partir del Censo General del 2005 (DANE). 
La llustración 3 muestra el porcentaje de participación laboral por edad desagregada y sexo. Se evidencia que la oferta de trabajo en el mercado laboral colombiano de los hombres es mayor que la correspondiente a las mujeres. Por otra parte, de acuerdo a la condición de migración se observa un patrón de mayor participación laboral en edades productivas por parte de los migrantes voluntarios y nativos; sin embargo, tanto la población desplazada forzada como la de los migrantes forzados por fenómenos naturales presentan un porcentaje de participación irregular, que sólo en edades jóvenes para los varones y en las avanzadas para ambos sexos, superan al porcentaje de oferta laboral de los migrantes voluntarios y nativos. En el mismo sentido, las diferencias en la oferta laboral entre los distintos grupos poblacionales son mayores para las mujeres que para los hombres, de manera que se identifica una menor proporción de participación laboral por parte de las mujeres desplazadas forzadas y forzadas por fenómenos naturales, frente a las mujeres de los otros grupos poblacionales.

Mujeres y hombres refugiados internos habrían vivenciado dificultades para integrarse en diferentes ámbitos, lo cual estaría acorde con la menor parti- cipación de los desplazados forzados con respecto a otros grupos poblacionales, en especial en las edades consideradas como las más productivas. Algunas de las barreras comunes a los refugiados internos es la carencia del documento de identificación para acceder al mercado laboral (tal como para acceder a los apoyos y beneficios a los que tienen derecho por su condición de desplazados forzados), pues en general, durante sus muchos años de residir en las zonas rurales para ellos $y$ ellas no era de vital importancia poseerlo, motivo por el cual algunas personas no accedieron al mismo, como en el caso de la mayoría de las mujeres desplazadas forzadas (Tovar \& Pavajeau, 2010). Igualmente, el trasladarse hasta una cabecera municipal para tramitar el documento de identificación puede ser complejo. Adicionalmente, en el evento del desplazamiento, y por ser para muchos de los desplazados forzados una situación de impacto imprevista, frecuentemente se les extravió su documento de identificación, o en el caso de los varones no tramitaron su libreta militar al no tener recursos para hacerlo o al no tener clara su situación de prestación de servicio militar; los cuales son en general algunos de los documentos requeridos para acceder a un trabajo.

Ilustración 3. Tasa de participación laboral por sexo, edad y condición migratoria en Colombia ${ }^{17}$

a) Tasa de participación laboral masculina

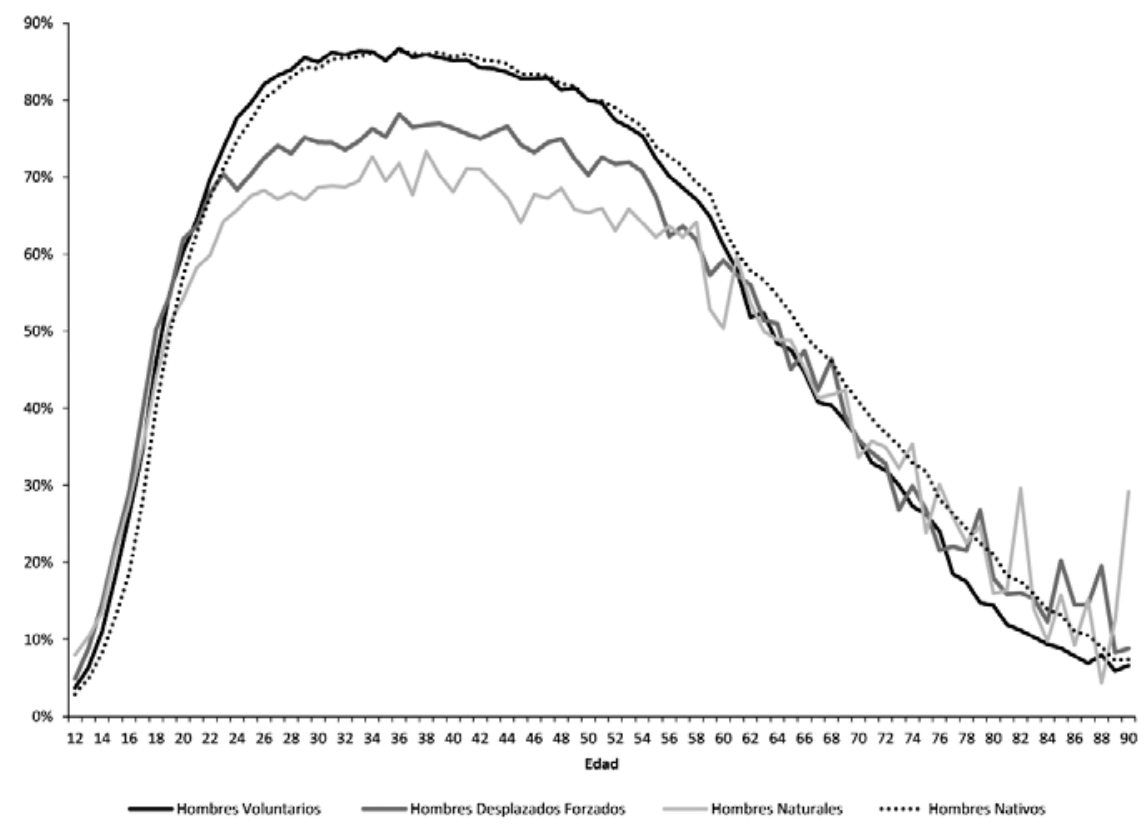

17 Fuente: Cálculos propios a partir del Censo General del 2005 (DANE). 
b) Tasa de participación laboral femenina

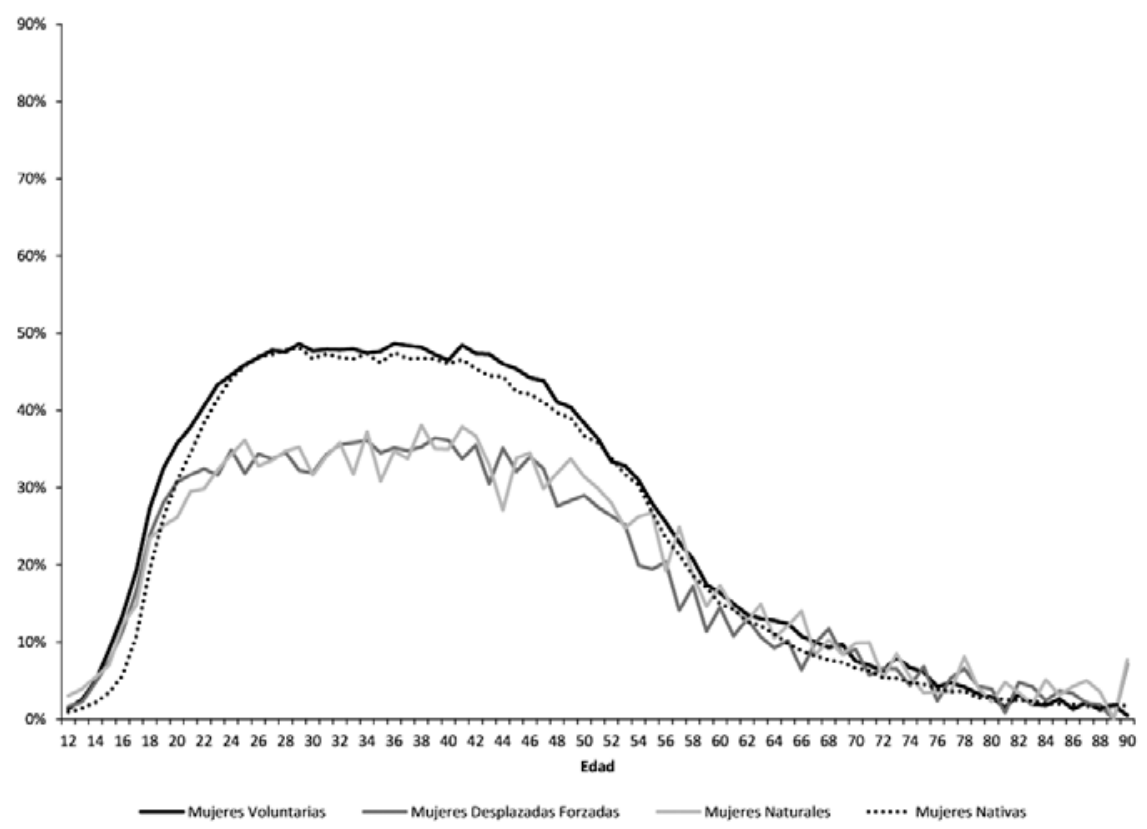

Los varones desplazados forzados, quienes en su mayoría han sido identificados como campesinos, presentaron una menor participación en el mercado laboral comparados con otros grupos poblacionales, lo cual podría deberse entre otros factores a que por su "saber hacer" no tienen cabida en el nuevo contexto. El nuevo mundo laboral les ofrece a los varones desplazados por la violencia escasos ambientes para las destrezas que han afianzado en su socialización (Ibáñez \& Moya, 2007; Ibáñez, Moya \& Velásquez, 2006; Tovar \& Pavajeau, 2010).

De otro lado, las mujeres refugiadas internas, en su mayoría campesinas antes del desplazamiento forzado, se dedicarían al igual que las otras mujeres a los oficios domésticos en su propia casa, lo cual en general no ha sido valorado como trabajo por parte de sus maridos, ni por la sociedad en general. Igualmente, las mujeres desplazadas forzadas se dedican también a desempeñar una posición activa en la búsqueda de apoyo familiar y social, así como para la consecución de albergue, pero dado su escaso nivel académico, desarrollo de destrezas y habilidades en los nuevos contextos que llegan a poblar y en el cual compiten con la población tradicionalmente pobre y vulnera- ble, podrían desalentarse de buscar trabajo dado que podrían ser estigmatizadas, al igual que los varones, por haber estado en medio del conflicto armado (Segura-Escobar \& Meertens, 1997).

Las secuelas en la salud mental de los desplazados forzados podrían afectar su capacidad de trabajar y de enfrentar diariamente las cicatrices que les dejó el conflicto armado. Estas secuelas se relacionan con patologías relacionadas con el estrés postraumático como la ansiedad, la depresión severa, el alcoholismo y la violencia intrafamiliar, que pueden manifestarse de diversas maneras de acuerdo a la edad y al género (Tovar, 2006; Juárez \& Guerra, 2011).

\subsection{Método de estimación de participación laboral}

Con el fin de precisar si existió una menor probabilidad para los desplazados forzados de participar $y$ encontrarse ocupados en el mercado de trabajo, en comparación con los otros grupos poblacionales analizados, se plantea utilizar un modelo de participación laboral. Este tipo de modelos pueden interpretarse como un análisis de costo-beneficio, en los 
que se considera que la participación laboral depende de las características propias de cada persona, tal como del contexto del hogar y laboral en que se encuentran inmersos. El estudio de los determinantes de la participación laboral ha sido materia de numerosos análisis, entre los cuales las metodologías más comunes son los modelos logísticos y probabilísticos, en los cuales se incorporan variables del individuo, hogar y contexto (Tenjo \& Ribero, 1998).

En la literatura frecuentemente se menciona la posibilidad de la existencia de una relación entre desempleo y participación laboral, dado que algunos individuos al no encontrar trabajo podrían abandonar el proceso de búsqueda y dejar de estar clasificados como miembros de la fuerza de trabajo. Además, en periodos de alto desempleo, las personas que podían estar pensando entrar al mercado laboral finalmente podrían cambiar de decisión. En este sentido, a los individuos que obedecen a los casos anteriormente expuestos, se les denomina como trabajadores desalentados, quienes no serían tomados en cuenta en las mediciones de desempleo (Tenjo \& Ribero, 1998, 26). Por tanto, para eliminar la selectividad que pueda representar la secuencialidad o el ordenamiento de primero tomar la decisión de participar o no en el mercado laboral y si el individuo que decide participar se ocupa o no, se plantea estimar un modelo logístico multinomial en el cual se consideran simultáneamente tres tipos de estados ocupacionales: inactivo, desocupado y ocupado (Núñez \& Ramírez, 2002; Uribe, Ortíz \& Correa, 2004).

El modelo teórico que sustenta este enfoque es el conocido modelo ocio-consumo. La modelación de las decisiones de participación laboral con una estrategia analítica multinomial supone que estas decisiones de los agentes son simultáneas y se encuentran sesgadas por la posibilidad de encontrar efectivamente empleo en el contexto en el que se encuentran inmersos (Uribe et al., 2004). La simultaneidad de las decisiones de participación laboral y el estado ocupacional en el que se encuentran es particularmente importante para la población de desplazados forzados, dado que se pueden presentar posibles sesgos de estimación si, como es común, se supone la secuencialidad de decidir participar y luego de si pueden conseguir o no trabajo, dado que al mismo tiempo se presentan múltiples alternativas o condicionantes. Dentro de las múltiples alternativas o condicionantes de la participación en el mercado laboral se encuentran: la duración de la búsqueda de empleo, la retribución al trabajo que podrían recibir, el acceso a redes sociales y canales de comunicación de oportunidades de empleo, el rol que desempeñan en el hogar, entre otros (Tenjo \& Ribero, 1998).

En este caso, se menciona la posibilidad de que exista relación entre desempleo y participación laboral, ya que al no encontrar trabajo, algunos abandonan el proceso de búsqueda y por lo tanto dejan de estar clasificados como miembros de la fuerza laboral. En el caso de algunos desplazados forzados, éstos podrían posponer su decisión de entrar al mercado laboral ante sus anhelos de retorno o reubicación. De este modo, la baja participación laboral de los desplazados forzados podría esconder el desempleo, debido a que los desplazados forzados podrían en mayor medida representar a trabajadores desalentados.

En general la ecuación de participación en el mercado laboral, se puede representar de la siguiente forma:

$$
P=f(\beta X+\mu)
$$

Donde $\mathrm{P}$ es una variable discreta que toma los valores del estado ocupacional, $\mathrm{X}$ es un vector de características observables del individuo, $\beta$ es el vector de parámetros de los efectos de cada una de las características contenidas en X sobre la decisión de participación y $\mu$ representa el efecto no observable sobre las características de participación.

En el modelo de regresión logística multinomial de participación laboral, la variable dependiente Y representa el estado ocupacional del j-ésimo individuo que adquiere los valores de: $1=$ inactivos, $2=$ desocupados y $3=$ ocupados; $^{18}$ y la $\mathrm{X}$ hace referencia a las variables explicativas. De esta forma, en el modelo logístico multinomial se estima el conjunto de

18 Los valores de la variable dependiente son escogidos de forma arbitraria dado que los estados ocupacionales no expresan ningún orden en particular. 
coeficientes $\beta^{(1)}, \beta^{(2)}$ y $\beta^{(3)}$, correspondiente a cada estado ocupacional Y:

$\operatorname{Pr}(Y=1)=\frac{\exp ^{\mathrm{x \beta (1)}}}{\exp ^{\mathrm{\alpha \beta (1)}}+\exp ^{\mathrm{x \beta (2)}}+\exp ^{\mathrm{\alpha \beta (3)}}}$

$\operatorname{Pr}(\mathrm{Y}=2)=\frac{\exp ^{\mathrm{x}(2)}}{\exp ^{\mathrm{x} \beta(1)}+\exp ^{\mathrm{x}(2)}+\exp ^{\mathrm{x \beta (3)}}}$

$\operatorname{Pr}(\mathrm{Y}=3)=\frac{\exp ^{\mathrm{x}(3)}}{\exp ^{\mathrm{x}(1)}+\exp ^{\mathrm{x}(2)}+\exp ^{\mathrm{x \beta (3)}}}$

Sin embargo, este modelo podría tener más de una solución, dado que más de un conjunto de $\beta^{(1)}, \beta^{(2)} y$ $\beta^{(3)}$ pueden conllevar a las probabilidades $Y=1, Y=2$ y $Y=3$. Con el fin de estimar una solución única del modelo, arbitrariamente se escoge como base los coeficientes de la categoría de los ocupados $\beta^{(3)}=0$, por lo que los restantes coeficientes $\beta^{(1)}$ y $\beta^{(2)}$ representarían el cambio relativo a la categoría ocupacional de los ocupados $Y=3$. Aun así, es posible que se presenten distintos valores en los coeficientes para cada una de las probabilidades estimadas de $\mathrm{Y}=1,2,3$, por lo tanto se podría obtener una única solución del modelo con la siguiente parametrización, tomando como base los coeficientes de la categoría correspondiente a los ocupados $\beta^{(3)}=0$ :

$$
\begin{aligned}
& \operatorname{Pr}(\mathrm{Y}=1)=\frac{\exp ^{\mathrm{x} \beta(1)}}{\exp ^{\mathrm{\alpha \beta}(1)}+\exp ^{\mathrm{\alpha \beta}(2)}+1} \\
& \operatorname{Pr}(\mathrm{Y}=2)=\frac{\exp ^{\mathrm{x} \beta(2)}}{\exp ^{\mathrm{x}(1)}+\exp ^{\mathrm{x \beta (2)}}+1} \\
& \operatorname{Pr}(\mathrm{Y}=3)=\frac{\exp ^{\mathrm{x} \beta(3)}}{\exp ^{\mathrm{x \beta (1)}}+\exp ^{\mathrm{\alpha \beta (2)}}+1}
\end{aligned}
$$

Entonces, la probabilidad de encontrar un individuo inactivo $\mathrm{Y}=1$, relativa a la categoría de los ocupa$\operatorname{dos} Y=3$ sería:

$\frac{\operatorname{Pr}(\mathrm{Y}=1)}{\operatorname{Pr}(\mathrm{Y}=3)}=\exp ^{\mathrm{x} \beta(1)}$

A esta expresión se le denomina Razón de Riesgo Relativo (RRR) y dado que $\mathrm{X}$ y $\beta^{(1)}$ son vectores iguales a $\left(\mathrm{x}_{1}, \mathrm{x}_{2}, \ldots \mathrm{x}_{\mathrm{k}}\right)$ y $\left(\beta^{(1)}, \beta^{(1)}, \beta_{2}^{(1)}\right)^{\prime} \mathrm{y},{ }_{3}$ la razón de riesgo relativo para una unidad de cambio en $\mathrm{x}_{1}$ sería:

$$
\begin{aligned}
& \exp _{1}^{\beta(1) X 1}+\ldots+\underset{1}{\beta(1)}(\mathrm{X} 1+1)+\ldots+\underset{\kappa}{\beta(1)} \mathrm{X \kappa} \\
& \exp _{1}^{\beta(1) X 1+\ldots+} \beta_{1}^{\beta(1) X 1}+\ldots+\underset{\kappa}{\beta(1) X \kappa}
\end{aligned}
$$

En consecuencia, el valor exponencial de cada coeficiente expresa la relación de riesgo relativo por cada unidad de cambio en la variable correspondiente. En este caso, el riesgo es medido como el riesgo estimado relativo a la categoría base de ocupados.

Es común en los modelos de participación laboral distinguir la población por sexo, más aun por el perfil diferenciado por sexo en la participación laboral de la población desplazada forzada, ya que los factores que determinan la participación de los varones no necesariamente son los relevantes para las mujeres y viceversa (Tenjo \& Ribero, 1998). Por consiguiente, en este artículo se plantea que las estimaciones de la participación laboral para varones y para mujeres se realicen por separado.

La pregunta central apunta a identificar si existieron dificultades en la inserción laboral de los individuos de acuerdo al estatus migratorio, para lo cual se incluyeron en la estimación variables dicotómicas para los migrantes voluntarios, migrantes forzados por fenómenos naturales y nativos, para comparar con el grupo base de desplazados forzados. De esta forma, se busca evidenciar si los desplazados forzados experimentaron mayores dificultades que los otros grupos poblacionales para participar en los mercados laborales colombianos por el hecho de "ser-estar desplazado forzado", dado que el trabajo se considera una actividad indispensable para su supervivencia.

A continuación se presentan otras variables que serán consideradas en la especificación del modelo de participación laboral. En cuanto a la posición en el hogar y el estado civil, García \& Pacheco (2000) y Núñez \& Ramírez (2002) evidenciaron para el caso mexicano y colombiano respectivamente, que podría existir mayor probabilidad de participar en el mercado laboral si un individuo es considerado como el(la) jefe(a) del hogar, o si se encuentra casado(a) o en unión libre o si alguna vez se había unido; debido a que podría tener mayores responsabilidades como proveedor(a) económico(a) para 
satisfacer las necesidades de consumo al interior del hogar. Particularmente, para este ejercicio escogimos como grupo base el de los(as) jefes(as) de hogar y construimos las variables dicotómicas que identifican al(a la) esposo(a) del(de la) jefe(a) del hogar o si es un miembro distinto de estos dos. También incluimos variables dicotómicas para los(as) solteros(as), viudos(as) y separados(as), tomando como grupo de comparación los(as) casados(as) o en unión libre.

Otro determinante comúnmente utilizado en este tipo de modelos es la edad, tratando de capturar efectos no lineales de esta variable por medio de un polinomio de grado dos. De este modo se considera que la probabilidad de participar aumenta con la edad (ciclo de vida) pues después de cierta edad, aunque matizado por las posibilidades de ahorro en el ciclo de vida, las decisiones de retiro y jubilación compiten con la de participación en el mercado laboral. En este artículo se estipula la forma cuadrática de la edad, puesto que podría capturar la forma de "U" invertida, con el fin de probar si existen rendimientos marginales decrecientes de la participación laboral con respecto a esta variable (Núñez \& Ramírez, 2002). Además, cabe aclarar que se restringe la muestra aleatoria a las personas de 12 años o más, dado que son consideradas como las que forman parte de la población en edad de trabajar.

También ha sido ampliamente documentado que la participación laboral depende en gran medida de la educación (Calderón \& Perlbach, 2000; García \& Pacheco, 2000; Núñez \& Ramírez, 2002), ya que una mayor escolaridad incrementa la probabilidad de participación en el mercado laboral. Por lo tanto, se considera el nivel de escolaridad, dado que en la medida que una persona se encuentre más calificada, podría tener mayor probabilidad de encontrar empleo y menor probabilidad de no participar en el mercado laboral. En este sentido, el signo esperado es ambiguo, puesto que las personas de menor escolaridad podrían tener menores pretensiones en materia laboral, realizando en general aquellos trabajos que las personas con algún nivel de escolaridad no estarían dispuestos a hacer (Calderón \& Perlbach, 2000). Asimismo, se podría identificar la pertenencia a una minoría étnica, ya que sus costumbres podrían afectar la inserción en el mercado laboral, dado que generalmente no cuentan con experiencia laboral para ejercer los oficios requeridos (Ibáñez, 2009).

Adicionalmente, podrían existir desbalances entre calificaciones laborales requeridas y áreas geográficas, lo que a su vez podría ocasionar que el proceso de búsqueda de empleo se alargue (Núñez \& Ramírez, 2002). Por este motivo, se considera que los factores pueden variar de acuerdo a la ubicación geográfica, que son especialmente importantes en el desplazamiento forzado, ya que pueden agregar un cúmulo de factores que no son fácilmente identificables, pero que se encuentran asociados a los departamentos y áreas metropolitanas, tales como las dispares tasas de desempleo que se evidencian a lo largo del territorio colombiano. De este modo, se podrían tener en cuenta variables dicotómicas para desagregar el efecto que podría haber tenido la distribución espacial y la segmentación laboral de acuerdo a la ubicación geográfica, tales como la variable dicotómica de residir en un área metropolitana o en un determinado departamento de Colombia.

\subsection{Resultados de la estimación del modelo}

La estimación del modelo logístico multinomial planteado se realiza con base en una muestra aleatoria del 5\% de la información del Censo de 2005, a partir de la población colombiana en edad de trabajar por separado para varones y para mujeres ${ }^{18}$. Inicialmente se estimó el conjunto de los coeficientes y del modelo logístico multinomial de participación laboral, donde la variable dependiente corresponde a los inactivos y desocupados, teniendo como grupo base el de los individuos ocupados. Dicha estimación se realiza con una matriz de covarianza robusta con el fin de evitar la presencia de heteroscedasticidad en la estimación de los coeficientes.

Los resultados generales de las estimaciones que se presentan en el Anexo (Tabla A- para varones y Tabla A- para mujeres) se consideran satisfactorios, ya que el pseudo- $\mathrm{R}^{2}$ que estima la medida del grado de ajuste de la regresión está en un rango

18 La muestra aleatoria del 5\% de la población en edad de trabajar considerada representó a 837.726 personas. 
relativamente alto para este tipo de estimaciones $\left(\mathrm{R}^{2}{ }_{\text {varones }}=0,29, \mathrm{R}_{\text {mujeres }}^{2}=0,20\right)$; además, los regresores de las estimaciones para varones y para mujeres son en conjunto estadísticamente significativos (Prob $\left.>\mathrm{Chi}^{2}=0,0000\right)$ y en general los coeficientes son también significativos a nivel individual.

Por simplicidad en la lectura de las estimaciones y para evaluar nuestra hipótesis central, se construye como línea base un individuo desplazado forzado (ya sea de sexo masculino o femenino), jefe de hogar, con educación primaria, que no perteneció a ninguna minoría étnica, con cónyuge (casado/unión libre), que residía en un área metropolitana, específicamente en Bogotá. En la Tabla 3 se muestran los efectos marginales estimados a partir de las probabilidades pronosticadas de los modelos logísticos multivariados de participación laboral para varones y correspondientemente en la Tabla 4 para la participación laboral de las mujeres; los cuales se calcularon en la edad promedio y en la línea base para las demás variables.

Al comparar entre los varones desplazados forzados en Colombia, específicamente los cónyuges con los jefes, la Tabla 3 muestra que los cónyuges tuvieron mayor probabilidad que los jefes de encontrarse inactivos en 2,3 puntos porcentuales y desocupados en 6,3 puntos porcentuales, así como presentan una probabilidad menor en 8,6 puntos porcentuales de encontrarse ocupados. De igual forma, al comparar con los jefes varones desplazados forzados, los otros miembros del hogar varones diferentes al cónyuge o al jefe aumentaron la probabilidad de encontrarse inactivos en 0,8 puntos porcentuales y desempleados en 5,4 puntos porcentuales, así como disminuyeron la probabilidad de encontrarse ocupados en 6,2 puntos porcentuales.

Entonces, entre los varones desplazados forzados en Colombia, los cónyuges y los otros miembros del hogar presentaron mayor probabilidad de encontrarse inactivos y desocupados, así como una menor probabilidad de ocuparse que los jefes. Nuestra hipótesis de lo que podría ocurrir es que los jefes varones desplazados forzados en Colombia necesitan participar en el mercado laboral para preservar su rol como proveedores económicos del hogar.
Tabla 3. Efectos marginales para los varones ${ }^{19}$

\begin{tabular}{|c|c|c|c|c|c|c|}
\hline & \multicolumn{2}{|c|}{ PEI } & \multicolumn{2}{|c|}{ Desocupados } & \multicolumn{2}{|c|}{ Ocupados } \\
\hline \multicolumn{7}{|c|}{ Cambio de posición en el hogar } \\
\hline \multirow[t]{2}{*}{ Jefe Cónyuge Jefe } & 0,023 & *** & 0,063 & *** & $-0,086$ & $* * *$ \\
\hline & $(0,002)$ & & $(0,006)$ & & $(0,006)$ & \\
\hline \multirow[t]{2}{*}{ Jefe Otro miembro } & 0,008 & *** & 0,054 & *** & $-0,062$ & $* * *$ \\
\hline & $(0,001)$ & & $(0,004)$ & & $(0,003)$ & \\
\hline \multicolumn{7}{|c|}{ Cambio de estado civil } \\
\hline \multirow[t]{2}{*}{ Casado Soltero } & 0,020 & *** & 0,037 & *** & $-0,057$ & $* * *$ \\
\hline & $(0,001)$ & & $(0,003)$ & & $(0,003)$ & \\
\hline \multirow[t]{2}{*}{ Casado Viudo } & 0,002 & & $-0,002$ & & 0,000 & \\
\hline & $(0,002)$ & & $(0,008)$ & & $(0,008)$ & \\
\hline \multirow[t]{2}{*}{ Casado Separado } & 0,003 & $\star \star *$ & 0,017 & *** & $-0,021$ & $* \star *$ \\
\hline & $(0,001)$ & & $(0,004)$ & & $(0,004)$ & \\
\hline \multicolumn{7}{|c|}{ Cambio de estatus migratorio por estado civil } \\
\hline \multicolumn{7}{|l|}{ Desplazado Voluntario } \\
\hline \multirow[t]{2}{*}{ Casado/Unión Libre } & $-0,003$ & $* \star *$ & $-0,051$ & $* * *$ & 0,054 & $* * *$ \\
\hline & $(0,001)$ & & $(0,005)$ & & $(0,005)$ & \\
\hline \multirow[t]{2}{*}{ Soltero } & $-0,005$ & ** & $-0,068$ & *** & 0,073 & $* * *$ \\
\hline & $(0,002)$ & & $(0,007)$ & & $(0,007)$ & \\
\hline \multirow[t]{2}{*}{ Viudo } & $-0,003$ & $* * *$ & $-0,050$ & *** & 0,054 & $* * *$ \\
\hline & $(0,001)$ & & $(0,006)$ & & $(0,006)$ & \\
\hline \multirow[t]{2}{*}{ Separado } & $-0,003$ & $* * *$ & $-0,059$ & *** & 0,063 & $\star * *$ \\
\hline & $(0,001)$ & & $(0,006)$ & & $(0,006)$ & \\
\hline \multicolumn{7}{|l|}{ Desplazado Nativo } \\
\hline \multirow[t]{2}{*}{ Casado/Unión Libre } & 0,001 & & $-0,047$ & $\star * *$ & 0,046 & $* * *$ \\
\hline & $(0,001)$ & & $(0,005)$ & & $(0,005)$ & \\
\hline \multirow[t]{2}{*}{ Soltero } & 0,003 & & $-0,063$ & *** & 0,060 & $\star * *$ \\
\hline & $(0,002)$ & & $(0,007)$ & & $(0,007)$ & \\
\hline \multirow[t]{2}{*}{ Viudo } & 0,001 & & $-0,046$ & *** & 0,045 & $* * *$ \\
\hline & $(0,001)$ & & $(0,006)$ & & $(0,006)$ & \\
\hline \multirow[t]{3}{*}{ Separado } & 0,002 & & $-0,055$ & *** & 0,053 & $* * *$ \\
\hline & $(0,001)$ & & $(0,006)$ & & $(0,006)$ & \\
\hline & Cambio e & dad & & & & \\
\hline \multirow[t]{2}{*}{ Edad } & $-0,002$ & $* \star *$ & 0,000 & *** & 0,002 & $* * *$ \\
\hline & $(0,000)$ & & $(0,000)$ & & $(0,000)$ & \\
\hline \multicolumn{7}{|l|}{ Cambio nivel educativo } \\
\hline \multirow[t]{2}{*}{ Primaria Ninguno } & 0,003 & $* * *$ & $-0,014$ & *** & 0,011 & *** \\
\hline & $(0,001)$ & & $(0,003)$ & & $(0,003)$ & \\
\hline \multirow[t]{2}{*}{ Primaria Secundaria } & 0,015 & *** & 0,020 & *** & $-0,035$ & $* * *$ \\
\hline & $(0,001)$ & & $(0,002)$ & & $(0,002)$ & \\
\hline Primaria Superior y Posgrado & 0,034 & *** & $-0,020$ & 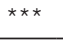 & $-0,014$ & $* * *$ \\
\hline & $(0,002)$ & & $(0,002)$ & & $(0,003)$ & \\
\hline
\end{tabular}

19 Fuente: Cálculos propios a partir de los datos del Censo de 2005 (DANE). 
Los asteriscos indican que el efecto marginal es estadísticamente diferente de cero a un nivel de significancia del *** 1\%, ** 5\% y * 10\%. Errores estándar por método Delta en paréntesis.

En la Tabla 3 también se encuentra que los varones desplazados forzados solteros o separados con respecto a los casados o en unión libre tuvieron mayor probabilidad de estar inactivos en 2 puntos porcentuales y desocupados en 3,7 puntos porcentuales, y disminuyeron la probabilidad de estar ocupados en 5,7 puntos porcentuales, respectivamente; al comparar los viudos con los casados o unidos no resultaron estadísticamente significativos los cambios en las probabilidades de encontrarse inactivos, ocupados o desocupados.

Así, entre los desplazados forzados los varones solteros y separados presentaron mayor probabilidad de encontrarse inactivos, pero los que decidieron participar en el mercado laboral presentaron también mayor probabilidad de encontrarse desocupados comparados con los varones que se encontraban en unión conyugal. Este efecto lo que podría reflejar es que, para los varones solteros sin mayores responsabilidades económicas en el hogar y para los varones separados que podrían contar con redes de apoyo familiar, el trabajo extra-doméstico no resulta tan necesario.

De esta forma, en cuanto a nuestra hipótesis central se identifica una selectividad negativa hacia los varones desplazados forzados en los mercados laborales colombianos, pues a diferencia de los varones migrantes voluntarios y nativos, evidenciaron una mayor probabilidad de encontrarse desocupados.

Esta mayor desocupación probablemente es debido a la estigmatización y discriminación que podrían enfrentar en la búsqueda de trabajo debido a su condición de "ser-estar desplazado" por el conflicto armado, al desconocimiento de lugares para la búsqueda de un empleo, a la falta de experiencia laboral, a que sus habilidades no son requeridas por los mercados laborales, a las escasas redes sociales que disponen en los lugares de destino, y en general, al proceso de disrupción que genera la migración, aún más cuando se trata de un exilio intempestivo (Ibáñez \& Moya, 2007; Ibáñez et al., 2006).

En cuanto al ciclo de vida de los varones, se identifica que, ante el aumento de un año en la edad de los desplazados forzados (evaluada en el promedio), disminuye la probabilidad de inactividad en la misma proporción en que aumenta la probabilidad de ocupación ( 0,2 puntos porcentuales).

Es decir que, nuestro desplazado base evaluado en la edad promedio de este grupo poblacional se encuentra en la etapa del ciclo de vida en la que aún son positivos los rendimientos marginales de un año más de edad. Por tanto, la probabilidad de participar en el trabajo de los varones desplazados forzados aumenta con la edad, debido a que por un lado podrían presentar mayor experiencia laboral, y de otro lado podrían experimentar mayores responsabilidades en el hogar.

Con respecto a la educación, al analizar el cambio en el nivel de escolaridad de un varón desplazado forzado, específicamente al comparar un varón desplazado con educación básica primaria con uno que no tuvo ningún tipo de educación, se estima que aumenta la probabilidad de inactividad $(0,3$ puntos porcentuales) y la probabilidad de encontrarse ocupado (1,1 puntos porcentuales), así como disminuye la probabilidad de desocupación (1,4 puntos porcentuales). Por otro lado, cuando estudiamos el cambio en el nivel de escolaridad de un varón con educación primaria a uno con secundaria, la probabilidad de encontrarse inactivo y desocupado aumenta (1,5 y 2 puntos porcentuales respectivamente), a su vez que la probabilidad de encontrarse ocupado disminuye (3,5 porcentuales). Asimismo, cuando pasamos de analizar un varón con educación primaria a uno con educación superior, aumenta la probabilidad de encontrarse inactivo $(3,4$ puntos porcentuales) y disminuye la probabilidad de encontrarse desocupado y ocupado ( 2 y 1,4 puntos porcentuales respectivamente). De esta forma, independientemente de las otras características sociodemográficas cuando mejora el nivel de escolaridad de los varones desplazados forzados las posibilidades de insertarse en los mercados laborales de los lugares de destino disminuyen, aunque no sustantivamente; a mayor nivel de escolaridad la probabilidad de encontrarse ocupado es menor. Este resultado podría explicarse por el peso que poseen en diferentes lugares la inversión hecha en educación; estas inversiones en capital escolar pueden no verse capitalizadas para el tipo de ocupaciones desempe- 
ñadas por los desplazados varones en su lugar de destino (Ibáñez et al., 2006).

En la Tabla 4 se evidencia que entre las mujeres desplazadas forzadas en Colombia cuando son cónyuges del jefe comparadas con las jefas de hogar, aumenta significativamente la probabilidad de encontrarse inactivas en 27,3 puntos porcentuales; además disminuye la probabilidad de encontrarse desocupadas en 5,2 puntos porcentuales, así como disminuye la probabilidad de encontrarse ocupadas en aproximadamente 22,1 puntos porcentuales.

De igual forma, entre las mujeres desplazadas forzadas, aquellas cuya posición en el hogar correspondía a otros miembros del hogar diferentes a la cónyuge del jefe o a las jefes, presentaron una probabilidad mayor de encontrarse inactivas en 10,6 puntos porcentuales y desocupadas en 1,5 puntos porcentuales, así como una menor probabilidad de encontrarse ocupadas en 12 puntos porcentuales.

Cabe resaltar que los mayores efectos marginales de las estimaciones son los de las mujeres desplazadas forzadas en Colombia que no fueron jefes de hogar, en especial las identificadas como cónyuges del jefe del hogar, quienes evidenciaron preservar en mayor medida su inactividad, probablemente por el rol de reproducción social que tradicionalmente han desempeñado en las labores domésticas y en el cuidado de los niños o por el control social que ejerce el jefe del hogar. Reforzando los hallazgos evidenciados en cuanto al rol socialmente construido de lo "femenino" asociado con el trabajo doméstico y el cuidado de los hijos, se identifica que entre las mujeres desplazadas forzadas, las solteras, separadas y viudas habrían participado más en el mercado laboral que las que se encontraban en unión conyugal.

Específicamente, en la Tabla 4 se observa que, al pasar de analizar las mujeres desplazadas forzadas casadas o en unión libre a cuando son solteras, viudas o separadas, disminuye la probabilidad de encontrarse inactivas en 8,$3 ; 2,6$ y 10,3 puntos porcentuales y aumentan la probabilidad de estar ocupadas en 5,$1 ; 1,8$ y 7,1 puntos porcentuales, respectivamente. Las solteras y las separadas tuvieron mayor probabilidad de encontrarse desocupadas comparadas con las que se encontraban en unión conyugal; en otro sentido, las diferencias en la probabilidad de encontrarse desocupadas entre las viudas y las que se encontraban en unión conyugal no resultaron estadísticamente significativas.

De esta forma, entre las mujeres desplazadas forzadas que decidieron participar laboralmente, las que no se encontraban en unión conyugal tuvieron mayor probabilidad de encontrarse ocupadas y desocupadas comparadas con las mujeres casadas/unidas. El resultado anterior podría reflejar que el trabajo extradoméstico es posible para las mujeres solteras sin mayores responsabilidades frente a las labores domésticas y al cuidado de los hijos, y para las mujeres separadas y viudas que cuentan generalmente con redes de apoyo familiar para el sustento y el cuidado de los hijos (Tovar, 2006).

Tabla 4. Efectos marginales para las mujeres ${ }^{20}$

\begin{tabular}{|c|c|c|c|c|c|c|}
\hline & \multicolumn{2}{|c|}{ PEI } & \multicolumn{2}{|c|}{ Desocupadas } & \multicolumn{2}{|c|}{ Ocupadas } \\
\hline \multicolumn{7}{|c|}{ Cambio de posición en el hogar } \\
\hline \multirow[t]{2}{*}{ Jefe Cónyuge Jefe } & 0,273 & *** & $-0,052$ & *** & $-0,221$ & $\star \star * *$ \\
\hline & $(0,004)$ & & $(0,005)$ & & $(0,005)$ & \\
\hline \multirow[t]{2}{*}{ Jefe Otro miembro } & 0,106 & $\star \star \star$ & 0,015 & $\star \star \star *$ & $-0,120$ & $\star * *$ \\
\hline & $(0,003)$ & & $(0,003)$ & & $(0,003)$ & \\
\hline \multicolumn{7}{|l|}{ Cambio de estado civil } \\
\hline \multirow[t]{2}{*}{ Casada Soltera } & $-0,083$ & $\star \star \star$ & 0,032 & *** & 0,051 & *** \\
\hline & $(0,003)$ & & $(0,004)$ & & $(0,004)$ & \\
\hline \multirow[t]{2}{*}{ Casada Viuda } & $-0,026$ & $\star * \star$ & 0,008 & & 0,018 & *** \\
\hline & $(0,006)$ & & $(0,007)$ & & $(0,007)$ & \\
\hline \multirow[t]{2}{*}{ Casada Separada } & $-0,103$ & $\star * \star$ & 0,032 & $\star * *$ & 0,071 & *** \\
\hline & $(0,004)$ & & $(0,005)$ & & $(0,005)$ & \\
\hline \multicolumn{7}{|c|}{ Cambio de estatus migratorio por estado civil } \\
\hline \multicolumn{7}{|l|}{ Desplazada Voluntaria } \\
\hline \multirow[t]{2}{*}{ Casada/Unión Libre } & $-0,031$ & $\star \star \star *$ & $-0,043$ & 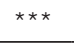 & 0,074 & *** \\
\hline & $(0,009)$ & & $(0,007)$ & & $(0,010)$ & \\
\hline Soltera & $-0,024$ & $\star \star \star$ & $-0,057$ & $\star \star \star$ & 0,081 & $* * *$ \\
\hline
\end{tabular}

20 Fuente: Cálculos propios a partir de los datos del Censo de 2005 (DANE).

Los asteriscos indican que el efecto marginal es estadísticamente diferente de cero a un nivel de significancia del *** $1 \%$, ** $5 \%$ y * 10\%. Errores estándar por método Delta en paréntesis. 


\begin{tabular}{|c|c|c|c|c|c|c|}
\hline \multirow[b]{2}{*}{ Viuda } & \multicolumn{2}{|l|}{$(0,008)$} & \multirow{2}{*}{$\begin{array}{c}(0,009) \\
-0,047 \\
\end{array}$} & \multicolumn{3}{|c|}{$(0,011)$} \\
\hline & $-0,029$ & $\star \star \star *$ & & $* \star \star$ & 0,076 & $* * *$ \\
\hline & $(0,009)$ & & $(0,008)$ & & $(0,010)$ & \\
\hline \multirow[t]{2}{*}{ Separada } & $-0,023$ & *** & $-0,058$ & *** & 0,081 & $* * *$ \\
\hline & $(0,007)$ & & $(0,009)$ & & $(0,011)$ & \\
\hline \multicolumn{7}{|l|}{ Desplazada Nativa } \\
\hline \multirow[t]{2}{*}{ Casada/Unión Libre } & 0,016 & * & $-0,045$ & $\star \star \star *$ & 0,029 & $\star * *$ \\
\hline & $(0,009)$ & & $(0,007)$ & & $(0,010)$ & \\
\hline \multirow[t]{2}{*}{ Soltera } & 0,017 & ** & $-0,058$ & *** & 0,042 & $* * *$ \\
\hline & $(0,007)$ & & $(0,009)$ & & $(0,010)$ & \\
\hline \multirow[t]{2}{*}{ Viuda } & 0,016 & * & $-0,048$ & $\star \star \star *$ & 0,032 & $\star \star *$ \\
\hline & $(0,008)$ & & $(0,008)$ & & $(0,010)$ & \\
\hline \multirow[t]{2}{*}{ Separada } & 0,015 & ** & $-0,059$ & $* * *$ & 0,043 & *** \\
\hline & $(0,007)$ & & $(0,009)$ & & $(0,010)$ & \\
\hline \multicolumn{7}{|l|}{ Cambio edad } \\
\hline \multirow[t]{2}{*}{ Edad } & $-0,013$ & $* * *$ & 0,000 & & 0,013 & $* * *$ \\
\hline & $(0,000)$ & & $(0,000)$ & & $(0,000)$ & \\
\hline \multicolumn{7}{|c|}{ Cambio nivel educativo } \\
\hline \multirow[t]{2}{*}{ Primaria Ninguno } & 0,036 & $\star * *$ & $-0,017$ & *** & $-0,019$ & *** \\
\hline & $(0,005)$ & & $(0,005)$ & & $(0,006)$ & \\
\hline \multirow[t]{2}{*}{ Primaria Secundaria } & $-0,121$ & $\star * \star$ & 0,019 & *** & 0,103 & *** \\
\hline & $(0,003)$ & & $(0,003)$ & & $(0,004)$ & \\
\hline \multirow[t]{2}{*}{ Primaria Superior y Posgrado } & $-0,238$ & $\star * *$ & $-0,008$ & *** & 0,245 & $\star * \star$ \\
\hline & $(0,006)$ & & $(0,003)$ & & $(0,005)$ & \\
\hline
\end{tabular}

Ahora bien, se observa en la Tabla 4 que las migrantes voluntarias, ya sea que se encontraran en unión conyugal, solteras, viudas o separadas, presentaron mayor probabilidad de encontrarse ocupadas $(7,4$ puntos porcentuales más las casadas, 8,1 puntos porcentuales más las solteras, 7,6 puntos porcentuales más las viudas y 8,1 puntos porcentuales más las separadas), menor probabilidad de encontrarse desocupadas (4,3 puntos porcentuales menos las casadas, 5,7 puntos porcentuales menos las solteras, 4,7 puntos porcentuales menos las viudas y 5,8 puntos porcentuales menos las separadas) e inactivas ( 3,1 puntos porcentuales menos las casadas, 2,4 puntos porcentuales menos las solteras, 2,9 puntos porcentuales menos las viudas y 2,3 puntos porcentuales menos las separadas) que las desplazadas forzadas. Las diferencias en las probabilidades de ocupación y desocupación de las mujeres al cambiar el estatus migratorio de ser nativas a desplazadas forzadas, fueron similares a las mencionadas anteriormente; sin embargo, las diferencias en las probabilidades de inactividad en este caso no resultaron tan robustas.

En este sentido, aunque en general las mujeres desplazadas forzadas participaron menos en el mercado laboral que las migrantes voluntarias, las que decidieron hacerlo afrontaron mayores dificultades en conseguir empleo. Este panorama evidencia los retos y realidades a los que se enfrentaron las mujeres desplazadas en Colombia, dado que al parecer participaron menos en el mercado laboral debido al esquema de rígidos roles en que se encontraron inmersas; además, las mujeres desplazadas forzadas que decidieron trabajar se vieron avocadas a escasas posibilidades de ubicarse laboralmente, lo que a su vez pondría de manifiesto las dificultades a las que pudieron haberse enfrentado para sobrevivir en los lugares de destino.

En cuanto al ciclo de vida de las mujeres, se identifica que, ante el aumento de un año en la edad de las desplazadas forzadas (evaluado en el promedio), disminuye la probabilidad de inactividad (en 1,3 puntos porcentuales), así como aumenta la probabilidad de ocupación en la misma proporción. De tal forma, la probabilidad de ocuparse aumenta con la edad de las mujeres desplazadas forzadas, probablemente porque se enfrentan a mayores responsabilidades en el hogar que les impone ocuparse para incrementar los recursos disponibles para la sobrevivencia económica de sus hogares.

Con respecto a la relación del nivel educativo con la participación laboral, al comparar una mujer desplazada con educación primaria a una que no tuvo ninguna educación, aumenta la probabilidad de que se encuentre inactiva una mujer sin educación $(3,6$ puntos porcentuales más con respecto a una mujer con educación primaria) y disminuye la probabilidad de que ésta participe en el mercado laboral (disminuye en 1,7 puntos porcentuales la probabilidad de encontrarse desocupada y disminuye en 1,9 puntos porcentuales la probabilidad de encontrarse ocupada). Del mismo modo, al aumentar el nivel de escolaridad de una mujer de primaria a secundaria y de primaria a educación superior aumenta la probabilidad de encontrarse ocupada (10,3 y 24,5 puntos porcentuales secundaria y superior, respectivamente) y disminuye la probabilidad de encontrarse inactiva $(12,1$ y 23,8 puntos porcentuales secundaria 
y superior, respectivamente). De esta forma, para las mujeres desplazadas capturadas por el Censo de 2005, la probabilidad de ocuparse aumenta cuando aumenta su nivel de escolaridad.

\section{Comentarios Finales}

Esta sección realiza el balance final de las estimaciones de la participación laboral de los desplazados forzados colombianos capturados por el Censo de 2005. La participación en la fuerza de trabajo es el resultado de una multiplicidad de factores. En este artículo estudiamos desde la perspectiva de la oferta, una serie de factores tanto para varones como para mujeres, independientemente de las otras condiciones sociodemográficas, para estimar cuáles pudieron ser los efectos de algunas características de interés en la participación laboral de acuerdo al estatus migratorio. Las estimaciones nos indican que existen limitaciones en la participación laboral que son particularmente sustantivas para las mujeres.

Asimismo, son las mujeres quienes parecen enfrentar con más frecuencia la "elección" de participar en el mercado laboral, para los varones no se presentan diferencias sobresalientes en la participación laboral, aunque algunas de sus características sociodemográficas la propician o la inhiben. Las diferencias entre las distintas características de los varones desplazados forzados tales como la posición en el hogar, edad y nivel de escolaridad fueron estadísticamente significativas en la participación laboral masculina, pero los efectos marginales no fueron considerables (las diferencias no superaron 8,6 puntos porcentuales); la mayor diferencia se evidencia en la mayor probabilidad de ocuparse de los jefes desplazados varones. Entonces, resalta la participación laboral del jefe varón como principal proveedor económico para satisfacer, al menos parcialmente, las necesidades básicas de la unidad doméstica.

Para las mujeres desplazadas forzadas parece ser importante la forma en que se articula el rol de la posición en el hogar y el de trabajadora remunerada. De este modo, las cónyuges, aunque también las otras mujeres miembros del hogar diferentes a las jefas, presentaron las mayores probabilidades de encontrarse inactivas (27,3 y 10,6 puntos por- centuales). Por tanto, para las mujeres desplazadas forzadas las responsabilidades domésticas atribuidas culturalmente a las cónyuges inhiben su participación en trabajos extra-domésticos.

Además, el nivel de escolaridad de las mujeres, específicamente para las desplazadas forzadas contar con estudios secundarios ó con educación a nivel superior o posgrado, disminuye sustantivamente la probabilidad de que se encuentren inactivas y a su vez aumenta la probabilidad de que se encuentren ocupadas. En cambio para las mujeres desplazadas sin estudios la situación es diferente, aumenta la probabilidad de encontrarse inactivas y a su vez disminuye la probabilidad de encontrarse ocupadas. En cuanto a la probabilidad de que las mujeres desplazadas se encuentren desocupadas, la probabilidad es mayor para las que poseen educación secundaria, seguida por las que poseen primaria.

Así, en el mercado laboral femenino el nivel de educación formal funciona como criterio de reclutamiento y lo hace en beneficio de las más educadas. De igual forma, la mayor escolaridad mejora la posición competitiva de las mujeres desplazadas forzadas en los mercados de trabajo, ya que pueden obtener mayor información sobre las oportunidades disponibles y la posibilidad de acceder a posiciones ocupacionales que elevan el costo de oportunidad de permanecer fuera del mercado ocupacional. Es por esto que el menor nivel educativo por parte de las mujeres desplazadas disminuiría las aspiraciones e incentivos a participar en los mercados laborales en los lugares de asentamiento.

Finalmente, para una futura investigación debería estudiarse si la participación laboral de los refugiados internos se encuentra limitada por el estigma del desplazamiento, ya que se evidenció en el estudio el carácter estructural de la mayor desocupación de los desplazados forzados, tanto varones como mujeres de todos los estados civiles. De ser así, el grupo poblacional de los refugiados internos habría experimentado discriminación y marginalización con respecto a los otros migrantes internos y a la población nativa, lo que podría tener implicaciones en la sobrevivencia económica en los lugares de asentamiento. 


\section{Referencias}

Calderón, M. \& Perlbach, I. (2000). "La probabilidad de participar en el mercado de trabajo y la exclusión social en Mendoza, Argentina”. En: Papeles de Población, 25: 121-150.

DANE - Departamento Administrativo Nacional de Estadística (2007). "Colombia: Estimación de la migración, Cociliación Censal 1985-2005". Disponible en: http://www.DANE. gov.co/files/investigaciones/poblacion/conciliacenso/6Mig racion1973 2005.pdf.

DANE - Departamento Administrativo Nacional de Estadística (2008a). Análisis de la estructura y composición de las principales variables demográficas y socioeconómicas del Censo 2005. Informe Final.

DANE - Departamento Administrativo Nacional de Estadística (2008b). Síntesis del proceso de cierre del Censo General 2005. Bogotá: DANE.

García, B. \& Pacheco, E. (2000). "Esposas, hijos e hijas en el mercado de trabajo de la Ciudad de México en 1995". En: Estudios Demográficos y Urbanos, 15(1): 35-63.

Ibáñez, A.M. (2009). El desplazamiento forzoso en Colombia: un camino sin retorno hacia la pobreza. Bogotá: Colección CEDE, Facultad de Economía, Universidad de los Andes.

Ibáñez, A. M. \& Moya, A. (2007). “Cómo deteriora el desplazamiento forzado el bienestar de los hogares desplazados: Análisis y determinantes de bienestar en los municipios de recepción”. En: Coyuntura Social, 37, 29-62.

Ibáñez, A. M., Moya, A. \& Velásquez, A. (2006). Hacia una política proactiva para la población desplazada. Bogotá: Universidad de los Andes, Secretariado Nacional de Pastoral Social Caritas Colombia.
IDMC - Internal Displacement Monitoring Center (2011). Internal displacement: Global overview of trends and developments in 2010, Ginebra, Informe de 2011, Internal Displacement Monitoring Center.

Juárez, F. \& Guerra, A. (2011). Características Socioeconómicas y Salud en Personas Pobres y Desplazadas. En: Psicologia. Teoria e pesquisa, 27(4), 511-519.

Lozano, M. \& Gómez, M. (2004). "Aspectos psicológicos, sociales y jurídicos del desplazamiento forzoso en Colombia”. En: Acta Colombiana de psicología, 12(4), 103-119.

Núñez, J. \& Ramírez, J. (2002). "Determinantes de la pobreza en Colombia". En: Documentos CEDE, Universidad de los Andes, 19

Segura-Escobar, N. \& Meertens, D. (1997). "Desarraigo, género y desplazamiento interno en Colombia". En: Revista Nueva Sociedad, Fundación Friedrich Ebert, 148: 30-43.

Tenjo, J. \& Ribero, R. (1998). "Participación, desempleo y mercados laborales en Colombia". En: Archivos de Macroeconomía, Departamento Nacional de Planeación, 81: 1-78.

Tovar, P. (2006). Las viudas del conflicto armado en Colombia: memorias y relatos. Bogotá: Instituto de Antropología e Historia y Colciencias.

Tovar, C. \& Pavajeau, C. (2010). "Hombres en situación de desplazamiento: transformaciones de la masculinidad". En: Revista de Estudios Sociales, Universidad de los Andes, (36): 95-102.

Uribe, J.; Ortíz, C. \& Correa, J. (2004), "Determinantes de las decisiones en el mercado laboral: La decisión de ser informal en Colombia”. En: Documentos de Trabajo - CIDSE, Universidad del Valle. 


\section{ANEXO: Resultados de estimación}

Tabla A. Participación de los varones en el mercado laboral ${ }^{18}$

\begin{tabular}{|c|c|c|}
\hline Log pseudolikelihood $=-229.337 .04$ & \multicolumn{2}{|c|}{$\begin{array}{r}\text { No. de obs }=405.701 \\
\text { Wald chi2(98) }=91.305 .21 \\
\text { Prob }>\text { chi } 2=0,0000 \\
\text { Pseudo R2 }=0,2927\end{array}$} \\
\hline $\begin{array}{c}\text { Actividad Económica } \\
\text { (comparación = Ocupados) }\end{array}$ & $\begin{array}{l}\text { Población Económicamente } \\
\text { Inactiva (PEI) }\end{array}$ & Desocupados \\
\hline Estatus Migratorio (base $=$ Desplazado) & & \\
\hline Voluntario & $\begin{array}{c}-0,2114^{* * *} \\
(0,0526)\end{array}$ & $\begin{array}{c}-0,7908^{* * *} \\
(0,0581)\end{array}$ \\
\hline Naturales & $\begin{array}{l}-0,1477 \\
(0,0927)\end{array}$ & $\begin{array}{c}-0,7931^{* * *} \\
(0,1275)\end{array}$ \\
\hline Nativo & $\begin{array}{c}0,0040 \\
(0,0512)\end{array}$ & $\begin{array}{c}-0,7044^{* * *} \\
(0,0552)\end{array}$ \\
\hline Rel. con JH (base = Jefe) & & \\
\hline Esposo JH & $\begin{array}{c}0,8067^{\star \star *} \\
(0,0423)\end{array}$ & $\begin{array}{c}0,5990^{* * *} \\
(0,0434)\end{array}$ \\
\hline Otro Miembro Hogar & $\begin{array}{c}0,3673^{\star \star *} \\
(0,0178)\end{array}$ & $\begin{array}{c}0,5130^{* \star *} \\
(0,0211)\end{array}$ \\
\hline Edad & $\begin{array}{c}-0,4245^{\star \star *} \\
(0,0021)\end{array}$ & $\begin{array}{c}0,0005 \\
(0,0027)\end{array}$ \\
\hline Edad $^{2}$ & $\begin{array}{c}0,0050^{* * *} \\
(0,0000)\end{array}$ & $\begin{array}{l}0,0000 \\
(0,0000)\end{array}$ \\
\hline Nivel Educativo (base $=$ Primaria) & & \\
\hline Ninguno & $\begin{array}{c}0,0974^{* * *} \\
(0,0289)\end{array}$ & $\begin{array}{c}-0,1630^{* * *} \\
(0,0331)\end{array}$ \\
\hline Secundaria & $\begin{array}{c}0,5520^{* * *} \\
(0,0120)\end{array}$ & $\begin{array}{c}0,2235^{\star * *} \\
(0,0177)\end{array}$ \\
\hline Superior y Posgrado & $\begin{array}{c}0,9262^{* * *} \\
(0,0166)\end{array}$ & $\begin{array}{c}-0,2055^{\star * *} \\
(0,0247)\end{array}$ \\
\hline Minorías Étnicas (base $=$ NO pertenece) & & \\
\hline Indígena & $\begin{array}{c}0,4163^{* * *} \\
(0,0311)\end{array}$ & $\begin{array}{c}-0,2364^{* * *} \\
(0,0487)\end{array}$ \\
\hline Negro & $\begin{array}{c}0,1159^{* * *} \\
(0,0155)\end{array}$ & $\begin{array}{c}0,3265^{\star * *} \\
(0,0221)\end{array}$ \\
\hline Otra Etnia & $\begin{array}{l}0,3030^{\star *} \\
(0,1484)\end{array}$ & $\begin{array}{c}0,1975 \\
(0,2268)\end{array}$ \\
\hline Estado Civil (base = Casado) & & \\
\hline Soltero & $\begin{array}{c}0,6885^{\star * *} \\
(0,0168)\end{array}$ & $\begin{array}{c}0,3884^{* * *} \\
(0,0216)\end{array}$ \\
\hline Viudo & $\begin{array}{l}0,0795 \\
(0,0692)\end{array}$ & $\begin{array}{l}-0,0173 \\
(0,0883)\end{array}$ \\
\hline Separado & $\begin{array}{c}0,1514^{* \star *} \\
(0,0391)\end{array}$ & $\begin{array}{l}0,1868^{* * *} \\
(0,0368)\end{array}$ \\
\hline Área Metropolitana & $\begin{array}{c}-0,2556^{* * *} \\
(0,0121)\end{array}$ & $\begin{array}{c}-0,4996^{\star * *} \\
(0,0197)\end{array}$ \\
\hline Constante & $\begin{array}{c}4,8943^{* * *} \\
(0,0634)\end{array}$ & $\begin{array}{c}-2,2001^{* \star *} \\
(0,0786)\end{array}$ \\
\hline Dummies Departamentales & Sí & Sí \\
\hline
\end{tabular}

18 Fuente: Cálculos propios de una muestra del 5\% del Censo de 2005 de varones de 12 años y más (DANE). Los asteriscos indican que el parámetro estimado es estadísticamente diferente de cero a un nivel de significancia del ${ }^{* * * *} 1 \%, *$ ** $5 \%$ y * 10\%. Errores estándar robustos en paréntesis. 
Tabla A. Participación de las mujeres en el mercado laboral19

Log pseudolikelihood $=-258.461 .1$

Número de obs $=438200$

Wald chi2(98) $=141132.18$

Prob $>$ chi2 $=0,0000$

Pseudo $\mathrm{R} 2=0,2025$

\begin{tabular}{|c|c|c|}
\hline $\begin{array}{c}\text { Actividad Económica } \\
\text { (comparación = Ocupadas) }\end{array}$ & $\begin{array}{l}\text { Población Económicamente } \\
\text { Inactiva (PEI) }\end{array}$ & Desocupadas \\
\hline \multicolumn{3}{|l|}{ Estatus Migratorio (base = Desplazada) } \\
\hline \multirow[t]{2}{*}{ Voluntaria } & $-0,4801^{* \star *}$ & $0,2195^{* * *}$ \\
\hline & $(0,0821)$ & $(0,0412)$ \\
\hline \multirow[t]{2}{*}{ Naturales } & $-0,2805^{*}$ & $0,1627^{\star *}$ \\
\hline & $(0,1632)$ & $(0,0727)$ \\
\hline \multirow[t]{2}{*}{ Nativa } & $-0,6519^{* * *}$ & 0,0055 \\
\hline & $(0,0789)$ & $(0,0401)$ \\
\hline \multicolumn{3}{|l|}{ Rel. con JH (base = Jefa) } \\
\hline \multirow[t]{2}{*}{ Esposa JH } & $-1,3202^{* * *}$ & $-1,0909 * * \star$ \\
\hline & $(0,0388)$ & $(0,0153)$ \\
\hline \multirow[t]{2}{*}{ Otro Miembro Hogar } & $-0,1265^{\star * \star}$ & $-0,5109^{* * \star}$ \\
\hline & $(0,0289)$ & $(0,0133)$ \\
\hline \multirow[t]{2}{*}{ Edad } & $0,3720^{\star \star \star}$ & $0,3418^{* * *}$ \\
\hline & $(0,0056)$ & $(0,0022)$ \\
\hline \multirow[t]{2}{*}{ Edad2 } & $-0,0051^{\star * *}$ & $-0,0042^{\star * *}$ \\
\hline & $(0,0001)$ & $(0,0000)$ \\
\hline \multicolumn{3}{|l|}{ Nivel Educativo (base = Primaria) } \\
\hline \multirow[t]{2}{*}{ Ninguno } & $-0,2833^{* \star \star}$ & $-0,1328^{* \star \star}$ \\
\hline & $(0,0676)$ & $(0,0209)$ \\
\hline \multirow[t]{2}{*}{ Secundaria } & $0,6054^{\star * *}$ & $0,6027^{\star * *}$ \\
\hline & $(0,0278)$ & $(0,0104)$ \\
\hline \multirow[t]{2}{*}{ Superior y Posgrado } & $1,0846^{\star \star *}$ & $1,5295^{\star * *}$ \\
\hline & $(0,0320)$ & $(0,0124)$ \\
\hline \multicolumn{3}{|l|}{ Minorías Étnicas (base = N0 pertenece) } \\
\hline \multirow[t]{2}{*}{ Indígena } & $-0,5806^{\star * \star}$ & 0,0051 \\
\hline & $(0,0835)$ & $(0,0259)$ \\
\hline \multirow[t]{2}{*}{ Negra } & $0,2990^{* * *}$ & $0,0349^{* *}$ \\
\hline & $(0,0302)$ & $(0,0137)$ \\
\hline \multirow[t]{2}{*}{ Otra Etnia } & 0,2917 & $-0,0496$ \\
\hline & $(0,2679)$ & $(0,1429)$ \\
\hline \multicolumn{3}{|l|}{ Estado Civil (base = Casada) } \\
\hline \multirow[t]{2}{*}{ Soltera } & $0,5515^{\star \star \star}$ & $0,3631^{* * *}$ \\
\hline & $(0,0323)$ & $(0,0142)$ \\
\hline \multirow[t]{2}{*}{ Viuda } & $0,1549^{* *}$ & $0,1108^{* * *}$ \\
\hline & $(0,0714)$ & $(0,0265)$ \\
\hline \multirow[t]{2}{*}{ Separada } & $0,6369^{* * *}$ & $0,4736^{\star * *}$ \\
\hline & $(0,0419)$ & $(0,0196)$ \\
\hline \multirow[t]{2}{*}{ Área Metropolitana } & $-0,8426^{\star \star \star}$ & $-0,4311^{* \star *}$ \\
\hline & $(0,0287)$ & $(0,0102)$ \\
\hline \multirow[t]{2}{*}{ Constante } & $-8,0000^{\star * *}$ & $-6,1861^{* * *}$ \\
\hline & $(0,1266)$ & $(0,0579)$ \\
\hline Dummies Departamentales & Sí & Sí \\
\hline
\end{tabular}

19 Fuente: Cálculos propios de una muestra del 5\% del Censo de 2005 de varones de 12 años y más (DANE).

Los asteriscos indican que el parámetro estimado es estadísticamente diferente de cero a un nivel de significancia del *** $1 \%$, *** $5 \%$ y*10\%. Errores estándar robustos en paréntesis. 